\title{
ON DEATH, TIME, AND MOVING IMAGES
}

$N_{\mathrm{B}}^{\mathrm{o}}$

Tow I Am Dead (2019) -Film by: Philipp

Bergmann and Isabel Bredenbröker

In the summer of 2018, I travelled back to my Ghanaian $\mathrm{PhD}$ fieldsite in the Volta Region, my third visit within two years. This time I came with a camera and a collaborator, Philipp Bergmann, to shoot footage for a film. My research investigates funerary practices and the materiality of death in Peki, an Ewe town community. But what had been intended as a critical filmic investigation into contemporary fieldwork practices and the role of the ethnographer took an unexpected turn. When my grandfather died on the third day of filming, I was in the middle of assisting an undertaker, attending funerals, investigating the work of the morgue staff, and picking up wandering souls. What else could I do, other than include the parallel death of a family member on another continent into what I was doing and filming? This paper offers a reflection of the different affective temporalities that I encountered whilst filming in this peculiar situation. It shows how a making of other-worldly time for the dead in Peki, the acceleration of global connections, and the containment of being in a place correlate in unexpected ways.

For Roland Barthes (1981), the photograph possesses a deadly quality, forever binding the subject as an image-object. Barthes describes how, in the act of being photographed, he experiences 'a micro-version of death' and feels himself 'truly becoming a spectre'. T.J. Demos sees this spectral quality in contemporary filmic and photographic artworks, such as those by Belgian artist Renzo Martens or South African photographer Pieter Hugo (Demos 2013). Here, the ghosts of colonial history come back to life. Yet, visual media, whether time-based or static, may also be perceived as endowed with animistic qualities that collapse otherwise distinct categories such as life and death, self and other. Christopher Pinney, working through the parallel histories of photography and anthropology, offers an account of the ways in which photography has not only served as a technology of objectification but has been instrumental in breaking down all sorts of temporalities between worlds for anthropologists and their subjects of study alike (Pinney 2011). Reflecting on the self-the ethnographer-as a mirror of others' perceptions and one's own assumptions of otherness, moving images can help to transgress the limitations of subjectivity and unmask the idea of sacrosanct individuality as Western mythology. The auto-ethnographic turn, in which the camera includes the anthropologist, amounts to what Barthes (1977) has termed the death of the author. Reflected in the moving image, these thoughts open up the potential of questioning assumptions about the other and the self and facilitate a new and possibly surprising view of the power of the encounter.

Zygmunt Bauman (2013 [1992]: 2) describes death as the 'absolute other of being, an unimaginable other, hovering beyond the reach of communication'. In the context of visual anthropology, the camera can serve as a twoway channel for attempting to communicate with a Beyond. In the process of making my film, I found death to be a surprising ally and the camera a valuable assistant. Bauman posits that 'whenever being speaks of that other (death), it finds itself speaking, through a negative metaphor, of itself' (ibid). Death does not allow 


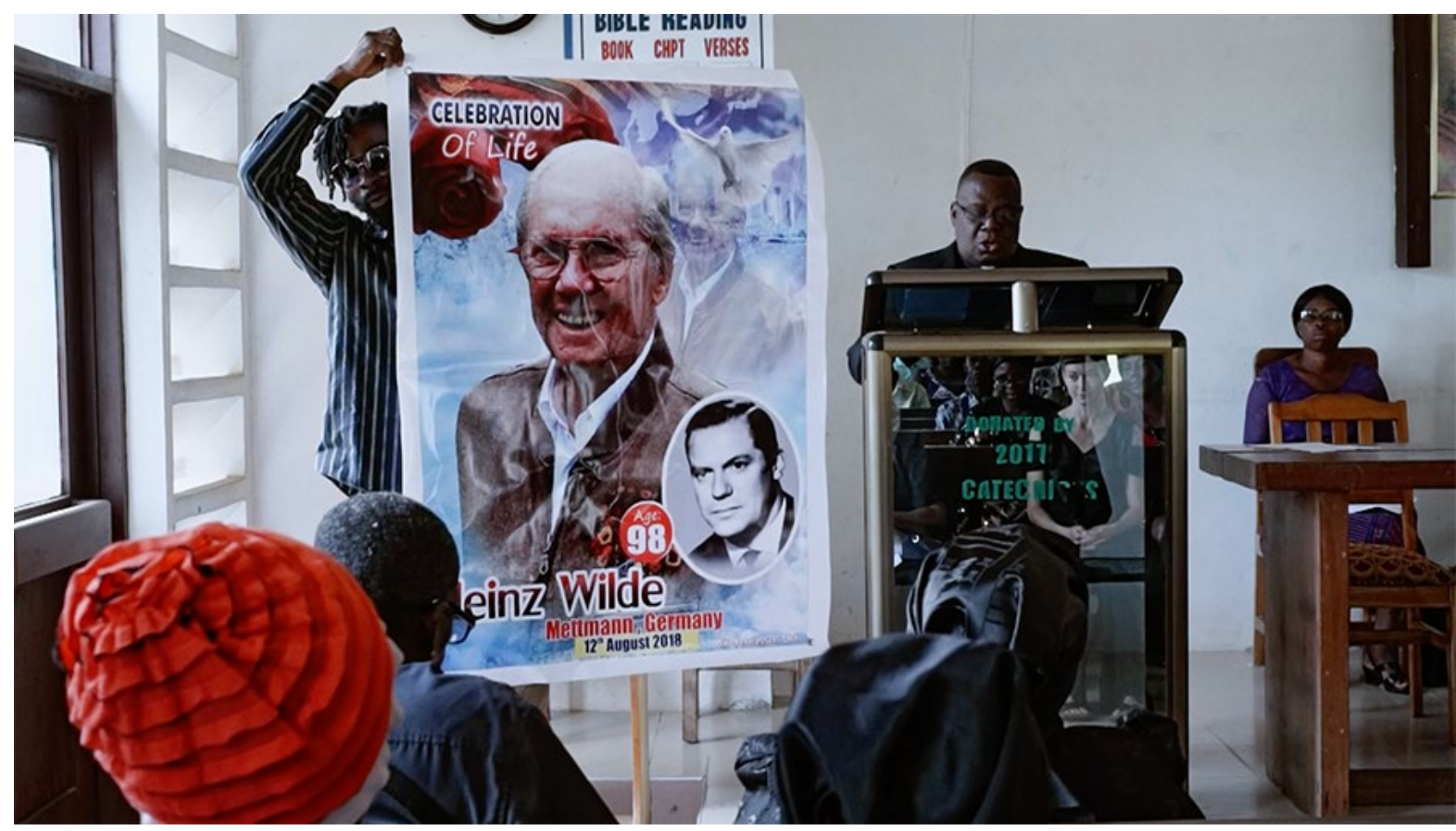

us to fill it with meaning. It throws us back onto our own image. In the history of anthropology, attributing meaning to the worlds of 'others' has meant walking a tightrope between violence and empathy, insight and attribution. My grandfather's death and subsequent funeral in Germany, which I could not attend, allowed me to consider anthropology's long-standing occupation with self-reflection. This selfreflective stance oscillates between navel gazing and productive critique. I was now able to examine it in practice, from a perspective that had gone off-script.

In the preparation process, before we even left Germany for Ghana, we had planned to let the anthropologist appear before the camera rather than behind it. We had envisioned the result as an anthropological film that concerns itself with death in an African culture, mediated through the presence of a European researcher. By doing so, we had hoped to avoid the pitfalls of ending up with a work that exploits the access of the camera, filming people who may not be in a position to fully consent or participate in the making of the film. Even before putting those ideas into practice, the approach presented a complex ethical and epistemological bind. We realised that we would have to address the role of anthropology in order to reveal where the film was unable to represent a multitude of other perspectives. At the same time, by choosing to focus on me, the anthropologist, we had put a white person at the centre of the film-was this possibly stealing the show? In Cannibal Metaphysics, Eduardo Viveiros de Castro (2014) tells the story of how he wanted to write the book 'Anti-Narcissus: Anthropology as Minor Science'. In the process of writing, he realized that this book was an impossible project. Narcissus stared at his own reflection in a pond, obsessed with what he saw, until he threw himself into the water and drowned. Instead of relieving anthropology of this curse, self-critique may in fact only reproduce the discipline's own reflection in the water. Our initial filmic concept was an attempt to be anti-narcissist, to deconstruct the researcher's authoritative power and position by including 
them. We had wanted to show the encounter that anthropological work always is and give an honest perspective on the strengths and weaknesses that such an encounter encompasses, from a position that we could represent. Yet, we paradoxically found ourselves caught between concerns of not using the camera as an aggressive tool in an environment where we were merely guests, and the unwanted effect of putting myself at the centre of the film, not wanting to make me the Narcissus of this story. Whatever we did seemed problematic in some way, leaving us less and less freedom to navigate.

Death, the absolute Other, acts as a sort of intensifying catalyst in the film and makes these paradoxes more acute. Our film is situated within a framework of image-making's 'doubletemporality'-the photographic image and its others which are history, cultural difference, and conceptualisations of death. During the making and preparation of the film, we were under pressure to acknowledge this without being reduced to silence. During the preparation phase, we assumed that the film's subject would be to frame these problems of representation visually. However, the sudden death of my grandfather midway through the production changed the terms of the project and placed us in a position to consider a more reflexive stance towards the story.

\section{POST-SCRIPTUM FIELDNOTES}

On Friday, December 22016 I met Mrs Lucy Atta for the first time. My fieldnotes for that day point out that she did not stop to greet me when we met. She went straight to the task that had been communicated to her: a white lady wants to learn about the dead, show her. Somewhere in that first encounter, the person I used to be was replaced by projections: images of German missionaries, British tradesmen, American wrestlers on TV, Jesus Christ, Chinese roadworkers, Premier League club emblems, and Gucci slides. The film reveals an image of the me-as-anthropologist hybrid. Sometimes I am allowed to be active, sometimes I am a bystander. I have to negotiate with people to be allowed to film, make payments and tolerate borders, forcing me to acknowledge my role with its abilities and limitations which were amplified by the presence of the camera. At the same time, photography serves as a multiplicator of perspective and agency. People take pictures of and with me, record ritual events, and photograph corpses, revealing how the spectre of film can serve a lot of different purposes which objectify (kill) and make understandable (enliven) at the same time. As an animistic and deadly medium, manipulating time in contrast to the constantly forward-flowing temporality of the living, photography can be both the problem and the solution when thinking about basic anthropological conundrums: who speaks, for whom, representing what?

What helped to permeate a seemingly impenetrable wall of otherness or difference was, first of all, the ability of local people to collaborate and participate in the taking of images, alongside the death of my grandfather and what followed. In front of the camera, I mourn my grandfather with the help of people in Peki, while his body is being interred thousands of kilometres away, in Germany, where a camera at the funeral would have been completely unthinkable. Here, there are things to be learned from experiencing my somewhat absurd, displaced mourning. Through a relative's death, I have, for a moment, acquired a social persona to the local community. I am in a sense more alive than a stranger or foreign researcher. I am allowed to use the same practices to mourn that I studied in the community during my time here. 
The last scene of the film shows how Lucy, trying to make a joke for the camera, dresses me in a frilly costume for corpses. I am visibly uncomfortable but play along. In an attempt to ease my tension, I try a joke: 'Now, I am Dead, yes?' She cracks up laughing, repeating the sentence back to me several times and then 'plays dead' by miming a corpse with a stiff bodily posture and tight facial features. This breaks my tension, and, with camera running, I feel as if I have truly transcended from life to death, finding here not horror but humour. At the same time, everything else that is other seems somehow less set in stone, even if only for an instant. Perspective, difference, and projections can be visualised and experienced consciously. Without the camera, this would not have been possible, none of these events would have taken place in the playful, humorous, and yet earnest way that they did. Just like the dead, who, in Peki, are carefully transported from life towards a new temporality of the dead, I am freed from the rules of the material world and can, happily, become a mirror on screen, leaving my living, breathing body, and its significations behind. This way, the figure of the anthropologist in this film can become a surface for revealing the absurdities and surprises of transcultural encounters, misunderstandings, and new ways of making sense in the face of finality.

\section{REFERENCES}

Barthes, Roland 1977. The death of the Author. In Roland Barthes. Image-Music-Text. London: Fontana Press.

Barthes, Roland 1981. Camera Lucida: Reflections on Photography. New York: Hill and Wang.

Bauman, Zygmunt 2013 [1992]. Mortality, Immortality, and Other Life Strategies. Cambridge: Polity.

Demos, T. J. 2013. Return to the Postcolony: Specters of Colonialism in Contemporary Art. Berlin: Sternberg Press.

Pinney, Christopher 2011. Photography and Anthropology. London: Reaktion (Exposures).

Viveiros de Castro, Eduardo 2014. Cannibal Metaphysics. Edited and translated by Peter Skafish. Minneapolis: University of Minnesota Press.

ISABEL BREDENBRÖKER

PHD CANDIDATE

GOETHE UNIVERSITY FRANKFURT

bredenbroeker@em.uni-frankfurt.de 